\title{
Transitions and translations from Afrikaans to English in schools of the Helderberg area
}

\author{
Jean Farmer \\ Centre for Teaching and Learning, Stellenbosch University, 7600 Stellenbosch, South Africa \\ Christine Anthonissen \\ Department of General Linguistics, Stellenbosch University, 7600 Stellenbosch, South Africa \\ Email: jeanlee@sun.ac.za; ca5@sun.ac.za
}

\begin{abstract}
This paper reports on the findings of a project that profiled the linguistic resources of learners with an Afrikaans-English bilingual background in order to determine features of a perceived process of language shift. The language repertoire and decisions on school enrollment of learners from Afrikaans homes that are registered in the English first language classes were investigated in a historically white, Afrikaans-only High School where recently English medium classes were introduced. During the past couple of years the language of learning and teaching in this school has been adjusted to fit the educational requirements of learners from linguistically and racially diverse backgrounds. Considering also the link between language and ethnicity, the linguistic preferences and patterns of language choice and language use of a selected group of 15- to 18-year-old learners were traced. Reported uses of English and Afrikaans in domains beyond the school, notably at home with relatives, are taken as indicative of linguistic identities. The patterns and preferences of learners from "coloured" communities indicate an extensive process of marginalisation of Afrikaans in families that formerly had a decidedly Afrikaans identity.
\end{abstract}

Keywords: language shift, language choice, family language, language of learning, Western Cape

\section{Introduction}

This paper reports on some of the outcomes of a research project on the extent to which language shift from Afrikaans as first language to English as first language in a Western Cape semi-urban community can be verified, and also quantified. The project investigated high school enrollment into English language-of-learning classes of a group of 15- to 18-year-old learners from families where the parents and grandparents have a strong Afrikaans ${ }^{1}$ first language (A-L1) identity. In addition to using choice of language-of-learning-and-teaching (LoLT) as an indicator of language shift, a selected sample of learners and parents were interviewed in order to obtain a qualitative assessment of relevant language attitudes ${ }^{2}$.

South African language education policy after 1994 was much less prescriptive than before, regarding enrollment in classes where the LoLT of young learners would not be the same as their first language (L1). Thus, it has become possible - and in some communities has become common practice - for A-L1 parents to enroll their children in English first language (E-L1) classes. In many 
cases, anticipating that this will be their LoLT choice for their children, A-L1 parents have raised their children in English, even though it is a second language (L2) to the family, and continued use of Afrikaans among the adults is still prevalent. These language choices appear to explain, at least in part, the perceived shift which is topicalised in this paper, that has been underway for some 20 to 25 years ${ }^{3}$ in a number of historically A-L1 "coloured" 4 communities. Even though the Western Cape Department of Education has since 2003 increasingly aimed to introduce and encourage the use of indigenous languages as LoLT during early primary school years, followed (where appropriate) by a switch to English during the senior phase at primary school, this practice is currently not obligatory. In other words, regardless of the home language and the L1 of a child, parents may choose the LoLT for their child, even if the child has limited or no proficiency in the LoLT of the school they select.

The current research project investigates language use and language attitudes at a multi-racial school (henceforth referred to as School A), where a majority of current learners are coloured. Until 1990 most South African schools were divided not only along racial lines, but also according to language. In this particular community on the outer boundaries of the Cape Town metropolitan area, schools had either English or Afrikaans as medium of learning and teaching. For white learners of the region, secondary schooling was available in either an Afrikaans medium school or one of two Afrikaans-English dual medium schools. For coloured learners of the region, secondary schooling was provided in Afrikaans, at a separate coloureds-only school. Since it was established in 1930 until 1990 the school where this research was undertaken was an Afrikaans medium school for white learners only. After 1990 with the gradual intake of a multi-racial learner component, demands for introducing English as language of learning increased so that by the late 1990s the school had become dual medium, offering the possibility of either Afrikaans or English as LoLT.

It is fair to assume that the choice of LoLT for coloured communities reflected the linguistic reality that, before 1990, Afrikaans predominated as the first and most widely used language of these communities. Prior to 1990 coloured parents who wanted their children to be educated through medium of English were obliged to find means of sending them further afield to secondary schools which offered dual medium or English only as LoLT. Post-1990, however, there is evidence that dominance of Afrikaans as the L1 of the community is changing: growing numbers of learners from traditionally Afrikaans homes in the coloured community are now enrolled in English first language classes. School A, responding to the changed profile of their learners, introduced English alongside Afrikaans as an option for LoLT. In the past 10 to 15 years the school has changed from being an Afrikaans medium school (which accommodated a limited number of English L1 learners) to a dual medium school with a very small proportion of learners in the Afrikaans section. At first, besides the five Afrikaans classes per year group, there was only one English LoLT class. Now, for every one Afrikaans medium class there are five English medium classes per year group. Notably, the apparent community language shift coincides with a shift from predominantly white learner enrolment to a significantly larger coloured learner enrolment at School A. Reflecting the changed regional demographics of the past 20 years, there is also a growing number of isiXhosa L1 learners who are enrolled in the English LoLT classes. Currently the racial breakdown of learner enrolment is approximately $60 \%$ coloured, $20 \%$ white and $20 \%$ black African; such racial diversity to a large extent coincides with language diversity.

A large number of coloured learners with Afrikaans home language backgrounds are enrolled at School A in the E-L1 classes. This is remarkable considering that the (mostly) A-L1 parents in this area have various possibilities of enrolling their children in Afrikaans LoLT classes in well- 
resourced schools: there are the Afrikaans medium classes in School A and there is a neighbouring Afrikaans medium-only school which, like School A, had been a "Model C" school (i.e. a school established for white learners under the pre-1994 regime and thus one that was privileged in terms of state allocated resources).

This study examines the linguistic resources and language choices of learners in a specific school, who come from a community with a noted degree of shift from Afrikaans monolingualism or Afrikaans-dominant bilingualism, to either English-dominant bilingualism or (in extreme cases) to English monolingualism. Finally, this study is also interested in whether the learners from strong Afrikaans backgrounds who are now enrolled in English LoLT classes, identify themselves in linguistic terms as E-L1, as A-L1, or as Afrikaans-English bilinguals (AE-L1). This article will report on the extent to which the learners with A-L1 parents use English as language of communication in other domains beyond the classroom. The study investigates the possibility that the decision of A-L1 parents to enroll their children in English medium classes has implications not only for the distribution of languages in the formerly Afrikaans medium school, but also for patterns of language use, language attitude and language identity in their homes, in the extended family and in other community organisations such as their religious affiliations. Although language preference and language choice of bi-/multilingual speakers does give information on the linguistic identities of the speakers, in this paper our interest is primarily in how these aspects of language identity inform on patterns of language shift across the community.

The paper will be organised as follows: section 2 will give a brief exposition of the theoretical field and terms of reference for this research; section 3 will describe the design of the project; section 4 will report on specific findings as they relate to the particular research questions that guided the project; section 5 will report on the general findings as they relate to findings on language shift elsewhere; and section 6 will draw conclusions and give an indication of how this work can be taken further.

\section{Language shift and language preference}

This study is located in the linguistic field of language shift. The study reported here relates to qualitative studies on language shift from Afrikaans towards English across three generations in a number of coloured communities in the Western Cape (Anthonissen and George 2003; Anthonissen 2009). It also relates to sociolinguistic aspects of McCormick's (2003) work on the specific variety of Afrikaans recorded in "Kaapse Afrikaans" communities in Cape Town. In this particular study, the learners are from families that would generally be identified as "middle class". Overall, the group of learners is the second generation to work towards completing a secondary school qualification; they come from families where the average level of formal education is steadily increasing, with growing numbers of learners continuing from secondary level to some form of certification at tertiary level.

Crystal (2003:259) describes language shift as "the gradual or sudden move from the use of one language to another, either by an individual or a group." According to Fishman (1989:206), in some circumstances language shift is virtually inevitable. He finds that "what begins as the language of social and economic mobility, ends, within three generations or so, as the language of the crib as well, even in democratic, pluralism-permitting contexts." This position seems to be endorsed by the preference of A-L1 parents in the community this article will report on, not only to enroll their 
children in the English medium classes of local schools, but even to use English as the primary language of parent-child communication right from birth.

The patterns of language shift under scrutiny here are of particular interest as the learners in focus use English as LoLT at school, while in their home community adults (including their parents) as well as many peers predominantly use Afrikaans. On a daily basis, across various social domains, these learners experience different patterns of use of the two community languages, which may range from English only, code-mixed English/Afrikaans to Afrikaans only. According to Milroy and Muysken (1995:6), "higher-order societal structures" decide the language behaviour in communities where different language varieties are represented. Even in communities such as Wesbank ${ }^{5}$ where indigenous languages (Afrikaans and Xhosa) are preferred to English in most contexts (Dyers 2007:119), learners realize that English is the lingua franca not only in the academic domain but also in other social domains.

In South Africa in general, as well as in the Western Cape in particular, the "higher-order societal structures" such as government, corporate concerns and elite social communities until very recently were made up by speakers of either English or standard Afrikaans. Since 1994, after the introduction of an inclusive democratic government representative of all ethnic and linguistic communities, the status of Afrikaans in public domains has certainly been challenged. Particularly amongst dialect speakers of Afrikaans in the Cape Town metropolitan area there is a strong tendency to revert to English rather than accommodate towards standard Afrikaans ${ }^{6}$. Relating to implicit demands of local societal structures, the governing body of School A has determined that learners in the E-L1 group have to speak English in classrooms. Although many parents have decided to introduce English as the L1 of their children, some close family members and friends still use Afrikaans, typically resulting in a fair deal of code-switching and code-mixing, which appears to be unexceptional in these communities. As in Wesbank, School A learners understand that, in their aspirations for further study and employment outside of their immediate community, English is the language of opportunity. In any case, learners are aware that English is a global lingua franca, which allows them to interact with others, not only with L1-speakers of indigenous South African languages, but also with foreigners in South Africa and abroad.

\section{Research design - measuring language shift}

In order to consider enrolment in the Afrikaans or English medium classes of a former Afrikaansonly school as an indicator of language shift, it was necessary to gain a clear impression of the patterns of language choice and language use of learners in the E-L1 classes who come from Afrikaans-English bilingual backgrounds where Afrikaans has long been the dominant community language.

\subsection{Research Questions}

The research intended to gauge linguistic resources and language choices of a selected group of students from a community where, already informally, a degree of shift from Afrikaans monolingualism or Afrikaans-dominant bilingualism to either English-dominant bilingualism or (in extreme cases) to English monolingualism had been noted. The learners in focus here had English as their only LoLT since early primary school. The general aim of the study was to establish the extent to which language shift can be verified, and to answer the question as to the language attitudes and linguistic identities of young learners with E-L1 as LoLT. In order to achieve this aim, the following specific research questions were formulated: 
Q1. What is the linguistic repertoire of the selected sample of learners in the E-L1 class, i.e. which languages does each learner know?

Q2. Which languages are typically used in various social domains: home, school, church and among peers?

Q3. Do learners switch from one language to another in different contexts, or is there a strong preference for use of one language variety rather than another across private and public domains of language use?

Q4. Which language preferences are expressed?

Q5. How are the language preferences of learners overtly motivated?

\subsection{Data Collection}

The target group of this project consisted of a sample of 303 teenage learners with an average age of 16 years (out of a total of 963 learners enrolled in the E-L1 classes for whom enrolment information was available), registered in grades 10 and 11 in a multi-racial, multi-lingual, former Model $\mathrm{C}^{7}$ high school in the Helderberg region of the Western Cape. Five different sources of data were used, the results of which were eventually integrated to achieve as complete an impression as possible on the practices, choices and preferences attached to the uses of English and Afrikaans in the coloured community of the Helderberg region. The five sources were (i) data from a central learner registry system (CEMIS), (ii) data from class lists provided by the relevant class group teachers, (iii) data from questionnaires (see Appendix 1) filled in by 303 Grades 10 and 11 learners, (iv) data from interviews with 23 of the learners who filled in the questionnaires, and (v) data from interviews with five parents of learners who had filled in the questionnaires. We will now briefly discuss these sources as well as the type of data obtained in each case.

\subsubsection{Centralised Educational Management Information System (CEMIS)}

First, for a broad overview, information made available by the Department of Education of the Western Cape through records on the Centralised Educational Management Information System was scanned. This confirmed the number of learners enrolled at the school, the number of learners enrolled in each grade, and the LoLT-group in which each learner was registered. Thus, it was possible to identify all learners who were enrolled in classes where English is the medium of instruction, even if there was no indication of what their particular home language was.

\subsubsection{Information sheets provided by teachers}

In order to select specifically those learners in the E-L1 Grade 10 and Grade 11 year groups whose home language was Afrikaans, information was drawn from lists provided by the register class teachers of each group.

\subsubsection{Learner questionnaires}

In addition to providing information directly by means of information sheets, teachers also assisted in administering questionnaires to 303 learners. The questionnaires were specifically designed with the research questions in mind, and collected information on language behaviour and on perception and attitudes towards various patterns of bilingual language use (see Appendix 1). The study focuses specifically on learners in the senior phase, as it aims also to determine what learners consider their linguistic identity to be by the time they reach the end of their school careers. Key questions for this study were developed with reference to Fishman's (1972:441) definition of domains and the importance of these in determining language shift. For Fishman a domain is an "institutional context" marked by "congruent behaviour occurrences". The 303 learners in the Grade 10 and 11 E-L1 classes (from A-L1 as well as E-L1 homes) were asked to 
complete the questionnaire under controlled conditions during a register class period in the "Home Room".

The data collected by means of the questionnaires provided information on learners' own patterns of language use in various domains. It also provided information on generational differences regarding the dominant language in families; in other words, the language proficiencies and preferences of the learners' grandparents, parents, their siblings and other close relatives. The questionnaires also gave a relatively broad perspective on the distribution of various languages in the particular group of learners. This information was collected not only for the specific insight it gives into individual histories, but also because it helped to establish that the phenomena the project intended to investigate are pervasive enough to justify using the selected instruments in deciding whether or not community language shift is actually in progress. It was clear from the questionnaires and interviews that some learners speak Afrikaans only at home, while they receive instruction at school in English. Questions 2 and 4 of the questionnaire (cf. Appendix 1) assisted in determining the languages of home and school, and whether any one of the two languages has a decisive effect on the speaker's choice of language in other social domains (among peers, in social networks, in religious practice, etc.) and in their intentions regarding future language choices.

\subsubsection{Learner interviews}

After the questionnaire data had been collected, 20 learners were invited for interviews with the primary researcher in order to gain qualitative information on their language attitudes, preferences and choices that would allow or disallow assumptions of language shift in their home communities. Learners were purposefully selected for interviews if they had indicated in the questionnaires that their parents often use Afrikaans in social domains (e.g. with family, friends, at work and in religious gatherings). The interviews were recorded and transcribed for easy reference.

In the interview, individual learners were reminded of the questionnaire which they had filled in about six weeks earlier and were asked to verify some of the information they had given there. The relatively long time lapse between completion of the questionnaire and the interview, was deliberate: possible conflict between what learners had written in the questionnaire and what they said later in the interview, could be checked to remove (as far as possible) answers that seemed tailored to what respondents thought would be "correct" rather than giving accurate information. Answers tailored to meet perceived expectations are not infrequent when matters of attitude and language choice in certain domains are raised. Therefore, responses to similar questions in the questionnaire and the interview had to be correlated. Most learners could either not immediately recall having filled in the questionnaire or could not recall their responses to specific questions. This was helpful in checking the reliability of answers. At the start of the interview learners were asked whether they preferred to have the interview in English or Afrikaans. They were assured that responses in Afrikaans or in code-switched English/Afrikaans were as acceptable as responses in English only. The questions that guided these interviews (see Appendix 2) referred to which languages participants know and to their own rating of their proficiency in understanding, speaking, reading and writing both languages. Particularly, participants were asked to reflect on the domains and kinds of discourses in which they use Afrikaans and/or English, with which addressees they were more likely to communicate in Afrikaans rather than in English and vice versa, and whether they endorsed their parents' choices regarding their children's language of 
learning. Particpants were also asked to indicate their attitudes to academic and social uses of English and Afrikaans, and their assessment of the value of each in considering their own futures.

\subsubsection{Parent Interviews}

Five A-L1 parents who have children enrolled in grades 10 or 11 in the E-L1 classes at School A were selected for interviews on their choices regarding the L1 of their children at home and at school. These interviews were conducted relatively informally and were thus not recorded. As the parents had consented to the data being used for the project, field notes were taken during, and elaborated directly after, the interviews. These parents were all considered "upper middle class" since they have had tertiary education (i.e. they have obtained diplomas or degrees at a training college or university). Although these parents were not fully representative of the parent body of the coloured learners at School A, the interviews were solicited because these parents had made considered choices regarding which languages to introduce their children to at various stages in their upbringing. They all indicated that, although they had themselves been raised A-L1, they had for a number of reasons opted to raise their children as English-dominant bilinguals.

Interviews with the parents were conducted in code-mixed English and Afrikaans as is customary in the parent community. The questions used to structure these interviews (see Appendix 2) were similar to those put to the learners, referring to which language(s) parents and children used in communication with one another in different scenarios and different kinds of contexts. They were asked to reflect on the uses of the two community languages among family members, among friends, and in public social domains. Specifically they were asked to give information on their own linguistic histories and to explain the choices they had made regarding the home language and language of learning of their children. As with the adolescents, the adults were asked to comment on language attitudes they harboured themselves and perceived among their children.

\section{Indicating language preference in choices of LoLT}

In this section we relate the information gained by means of the various research instruments to the specific questions that were developed to structure the investigation of how choices regarding LoLT may be indicators of language shift.

\subsection{Linguistic repertoires}

The first research question (see Q1 in section 3.1) which relates to the linguistic repertoires of the selected sample of learners, intended to establish whether the learners in the E-L1 classes are proficient in both Afrikaans and English, and if so, whether their English proficiency is equal to their Afrikaans proficiency. The answers to this question could assist in testing the hypothesis that a significant number of A-L1 families currently raise their children to be E-L1. For instance, if it were found that there is increased enrollment in E-L1 classes and that learners consistently rate their proficiency in Afrikaans lower than in English, it could be read as confirmation that language shift from Afrikaans to English as community language is indeed underway.

The CEMIS records reveal the distribution of the two languages of learning and teaching (English and Afrikaans) offered by School A. Although learners in the school are largely from the Afrikaans-dominant communities in the area, $731(76 \%)^{9}$ (of the full complement of 963 learners in grades 8 to 12$)$ are registered in the E-L1 classes, and $232(24 \%)$ are in the A-L1 classes. Of the 389 learners registered in grades 10 and 11, 162 grade 10s and 141 grade 11s 
(303 in all, $=78 \%$ ), are registered in E-L1 groups; 53 grade 10s and 33 grade $11 \mathrm{~s} \mathrm{(86} \mathrm{in} \mathrm{all,} \mathrm{=}$ $22 \%$ ) are registered in A-L1 groups. This information is summarised in Table 1 below:

Table 1. CEMIS data: Learners enrolled in grades 10 and 11

\begin{tabular}{|c|c|c|c|}
\hline Grade & E-L1 & A-L1 & Total \\
\hline 10 & $162(75 \%)$ & $53(25 \%)$ & 215 \\
\hline 11 & $141(81 \%)$ & $33(19 \%)$ & 174 \\
\hline & $303(78 \%)$ & $86(22 \%)$ & 389 \\
\hline
\end{tabular}

According to the data presented in Table 1, an average of $78 \%$ of the selected group of learners are enrolled as E-L1, while $22 \%$ are enrolled as A-L1. Enrollment in the E-L1 group indicates choice of LoLT, but does not indicate home language or L1 proficiency in English. As can be seen from Table 1, only $22 \%$ of learners are registered in the A-L1 classes, which is well below the regional average of $55.3 \%$ of A-L1 speakers (2002 census data). Considering that the school most likely represents a community where more than $55.3 \%$ are A-L1, such figures in registration of grade 10 and 11 learners at School A seem to suggest that language shift from A-L1 to E-L1 is already well underway.

Questionnaires and interviews collected from this particular group confirmed that all the E-L1 registered learners ${ }^{10}$ are bilingual speakers of English and Afrikaans, while some are also proficient in languages such as isiXhosa, German and Portuguese. Questionnaire data showed that $78 \%$ of the learners registered in E-L1 classes are from A-L1 homes. However, the majority of these learners identified themselves as E-L1 regardless of their home language. Of the 20 learners who were interviewed, $17(85 \%)$ self-reported weaker Afrikaans compared to English proficiency, two (10\%) self-reported stronger Afrikaans compared to English proficiency, and one (5\%) self-reported equal proficiency in English and in Afrikaans. Although self-assessment of language proficiency on its own is not a reliable measure of level of proficiency, it is an indicator of how speakers perceive their ability to interact and also their language identity. These issues were of specific interest in this project. In self-assessment, no learners indicated that they had low proficiency in Afrikaans. Nevertheless, a strong preference for English was pronounced.

\subsection{Different languages in different domains}

The second research question (see Q2 in section 3.1) sought to ascertain which languages are most commonly used in various domains of learners' home communities. Besides the LoLT at school, our interest was in which of the languages in their repertoire learners use among their family members, in their circle of friends and in their religious practices. Participants' answers in the section of the questionnaire which addressed the second research question, confirmed the hypotheses that language shift is evident in that (i) older members of the learners' home communities are predominantly A-L1 speakers, (ii) younger members of these communities are predominantly E-L1 speakers, and (iii) public domains such as local churches are increasingly replacing Afrikaans with English in their services and other gatherings.

Questions 2, 4 and 5.2 of the learner questionnaires (see Appendix 1) probed for information that would assist in answering the second research question. Learners indicated which languages they used in various domains (q.2), which they used with various close family members (q.4), and which they used with their peers (q.5.2). Not surprisingly, English was reported as the language of the classroom. No learner mentioned code-switching between English and Afrikaans as a classroom practice, except in the classes where Afrikaans is taught as "first additional language" 
and where the expectation is that the LoLT will be Afrikaans as well. Learners' responses in the questionnaires and interviews indicated which languages are used among their family members at home, as well as which are used across other social domains. In social interactions with peers, $50 \%$ of those interviewed reported that they use English only, whereas the remaining 50\% reported that they use Afrikaans and English. In cases where learners have friends who do not attend the same school as they do, the language of interaction is more likely to be Afrikaans. As this is a community where social identities are still strongly marked by religious affiliation, the questionnaire included specific questions regarding the languages used in these domains. Here learners reported that at the mosque or in church activities they are seen as English youngsters and addressed as such. One learner indicated that there are also isiXhosa-L1 speakers at their church gatherings, and that therefore the language of communication had to be English.

According to data collected with the questionnaires, $26 \%$ of the learners use Afrikaans as home language. Nevertheless, on closer investigation it appears that there are a variety of different language practices in family interactions. Neither questionnaire information nor what transpired from interviews, indicated use of only English or only Afrikaans as home language. Information on the patterns of language use in family interactions is summarised in Table 2. Regarding the languages most used with members of their immediate family, the group of 229 E-L1 learners from A-L1 homes indicated that with their siblings they mostly use English (58\%), with a tendency towards code-switching (35\%). With their parents and grandparents learners were more likely to alternate between using both English and Afrikaans (52-54\%), than to use only Afrikaans or only English. Also, learners tended to use more Afrikaans only (26\%) than English only (22\%) with grandparents, and slightly more English only (25\%) than Afrikaans only (21\%) with their parents. Finally, they indicated that with other members of the family they are more inclined to use Afrikaans only (46\%) or English/Afrikaans alternately (38\%) than English only (16\%).

Table 2. Averages of grade 10 and 11 learners' use of language with family members

\begin{tabular}{|l|c|c|c|c|}
\hline Language used & Siblings & Parents & Grandparents & $\begin{array}{c}\text { Other family } \\
\text { members }\end{array}$ \\
\hline English & $133(58 \%)$ & $58(25 \%)$ & $51(22 \%)$ & $36(16 \%)$ \\
\hline Afrikaans & $17(7 \%)$ & $48(21 \%)$ & $59(26 \%)$ & $106(46 \%)$ \\
\hline Eng/Afr code-switching & $79(35 \%)$ & $123(54 \%)$ & $119(52 \%)$ & $87(38 \%)$ \\
\hline
\end{tabular}

Considering that at least $78 \%$ of learners registered in E-L1 classes have Afrikaans family backgrounds, one can assume that at school these learners are in contact with English and code-switched Afrikaans/English, whereas at home they are in contact with Afrikaans and code-switched Afrikaans/English. Although many of the learners' grandparents are A-L1, the responses in the questionnaires indicated that the older generation accommodates the younger in that almost $75 \%$ of the A-L1 grandparents address their E-L1 grandchildren in English. Although many still use a fair amount of Afrikaans in the domain of home and family, younger family members are encouraged by older family and community members to use English as their primary language. In fact, almost $70 \%$ of the learners who identified their home domain as Afrikaans due to the L1 of their parents, speak mostly English or code-switch between English and Afrikaans. Some of the ways in which the learners are encouraged to use English are direct, for instance when a mother instructs her daughter not to use Afrikaans on the street. Other ways of encouraging use of English are more indirect; for example, when youngsters are addressed in English, when they overhear adults' appreciation of the value of English, 
when they are praised for their fluency in English or when they identify with English L1 icons.

\subsection{Individual patterns of language use}

The third research question (see Q3 in section 3.1) sought to determine which language(s) each learner actually uses, regardless of what the dominant language of a given domain may be. Data from the questionnaires as well as from interviews with learners and their parents, indicated that English is the language in their repertoire which they use more widely and with more confidence. Learners were frank about their knowledge and use of the two community languages, but were also upfront about the value they attach to English in terms of prestige and their expectations that the language will improve their life chances. For example, when asked about this in the interview, one learner who intends to study further at Stellenbosch University where Afrikaans is still widely used as LoLT, responded with (1):

I feel English will (help me) because more of the people will speak English, I feel, in that field (engineering). Or to most of the people, to socialise, English will be best.

Learners between the ages of 15 and 18 in the E-L1 classes do not code-switch excessively in the classroom. Although it is clear that code-switching is a regular practice in other domains, English dominates in the personal use of the respondents in this project. Our observation is that there is more code-mixing when Afrikaans is the matrix language ${ }^{11}$ than when English is the matrix language (see also section 5.5). For example, compare (2) below, where Afrikaans is the matrix language, and (3), where English is the matrix language:

(2) Hulle ken mos beter as ek en correct my left, $\underline{\text { right }}$ en $\underline{\text { centre }}$ as ek verkeerd praat. Engels is mos hulle first language, nie myne nie. [They know (English) clearly better than I (do) and correct me left right and centre if I speak incorrectly. English is clearly their first language, not mine.]

(3) It is seker the best decision but it depends on the individual. You must $\underline{\text { mos }}$ feel comfortable with your language.

(Here seker and $\underline{\text { mos }}$ are discourse markers: seker = most probably; $m o s=$ clearly]

Examples like (3), where Afrikaans words were inserted into predominantly English discourse occurred much less frequently in the data than examples similar to (2), where English words and phrases were inserted into predominantly Afrikaans discourse.

\subsection{Language preference, language attitude}

The fourth research question (see Q4 in section 3.1) sought to establish explicit language preferences of the group of 229 young respondents, seeking specifically to gauge the general attitudes they harbour towards each of the languages in their repertoire. Positive attitudes to English as the LoLT were reported throughout. In the learner interviews only one learner expressed an openly negative attitude towards Afrikaans and an unwillingness to use it. The value learners attach to E-L1 in spite of an Afrikaans background at home, not only endorses the linguistic choice of parents but can also be read as an indication that the language shift which is

already clear from anecdotal evidence and from the CEMIS data of School A, is unlikely to be reversed. 
Although the interviewed parents defended their choice of enrolling their children in the E-L1 classes, they all indicated that they wanted their children to be proficient in Afrikaans as well as in English. The learners were slightly more hesitant in expressing positive attitudes to Afrikaans, embracing the choices their parents had made and signalling an awareness of the higher status English has in their circle of friends.

\subsection{Explaining language preference}

The fifth research question (see Q5 in section 3.1) is an extension of the fourth: if learners have a pronounced preference for English, our interest is in how this preference is motivated. An answer to this question would also give an indication of how fixed the perceived shift may be, for example, whether it could be reversed or would it only be partial. Instead of completely replacing Afrikaans, a partial language shift from an Afrikaans home language to bilingualism could have the effect of maintaining the community language and at the same time opening up opportunities for intercultural communication and social mobility across linguistic boundaries. In motivating her preference for using English, even when she has virtually L1 Afrikaans proficiency, a learner who was interviewed expressed herself as follows:

(4) It will be English because it looks more ... it's better for the person that if he has English, because if you got Afrikaans or a mix, then he has a slang. It's not, doesn't look so good when they speak.

And where the learners feel their Afrikaans proficiency is not up to standard, they motivate their preference for English as illustrated in (5) and (6):

(5) Sometimes I have to think a lot before what I'm going to say, because it's Afrikaans. So in English I automatically know what I'm going to say.

(6) Like in Afrikaans there's a few words that "OK, what is this?" But English I automatically know. That is much more easier for me. ${ }^{12}$

\section{Features of language shift reflected in LoLT choices}

In this section we will consider specific information provided in answer to the questions on language repertoire, language choice and language attitude of learners and their parents (as set out in section 4), and discuss some of the salient features of the language shift that is evident in the LoLT choices of the Afrikaans/English coloured community in the Helderberg region. Reference will be made to studies of language shift elsewhere in order to gain a better understanding of the kinds of language choice and language use that are developing in the particular community.

\subsection{Increased enrollment in English L1 classes}

According to the 2001 census (Stats in brief 2002:17-18) Afrikaans is the L1 of the majority of coloured people living in the Western Cape. In terms of numbers of speakers, English ranks only fifth (at 8.2\%) among the eleven official languages as home language in South Africa, even if it is unchallenged as the lingua franca in media, business and politics. Among the three most commonly used home languages in the Western Cape, English ranks third after Afrikaans and isiXhosa. Afrikaans is the language most widely used as L1 in the region. From 1996 to 2007, Afrikaans as first home language showed a decline of 3.9\%, from 59.2\% to 55.3\%, in the Western Cape (largely in the white and coloured sections of the community). During the same period there 
was a decrease of $1 \%$ (from $20.3 \%$ to $19.3 \%$ ), in the use of English as first home language in the region across all racial groups. Nevertheless, schools accommodating learners from the coloured communities across the Cape Town metropolitan area have recorded a marked increase of subscription in classes with English as medium of instruction.

In School A, registration numbers of learners in the E-L1 section of each year group confirmed this trend: out of 389 learners registered in Grades 10 and 11, 303 were registered in the E-L1 section; of the 229 with either English or Afrikaans as home language, the teachers' information list indicated that $141(61.6 \%)$ came from A-L1 homes. Such indication of language preference through registration in the E-L1 rather than the A-L1 section, is consistent with Fishman's (1989:206) suggestion that parents often select the language of social and economic mobility to improve the life chances of their children. It is also consistent with Milroy and Muysken's (1995:6) finding that "higher-order societal structures" have a deciding influence on language behaviour, such as in this case, the linguistic choices families make in deciding on educational opportunities for their children.

\subsection{Language shift as loss of a dominant language}

Studies of language shift elsewhere in the world mostly report on the loss of a minority language in favour of the dominant community language, such as studies on the fate of Turkish in Austria (Romaine 2000) or of Chinese in the British Tyneside community (Wei 1994). In the South African context Afrikaans and English, along with nine other languages, constitutionally share equal status as official languages; in the Western Cape three of these languages are widely used and thus supported by the regional government. What is remarkable about the apparent language shift in the Cape Town metropolitan area, is that the majority language of the region is the one under threat. Anthonissen (2009:17) noted that language shift amongst coloured families "in the Cape metropolitan area is not related to geographical movement of a linguistic community" such as one finds in migrant or refugee communities. This study reiterates that finding since most of the parents of learners in this study grew up in the very area where they are currently living; thus, there has been no migration to an area where English is the dominant language of a new community.

Between 1925 and 1994 Afrikaans was the only language to challenge the position of English as lingua franca in the country, as these two languages of European origin were the only official languages. With considerably more L1 speakers than English, and with governmental powers largely in the hands of L1 speakers of Afrikaans, it is not surprising that after $1948^{13}$ Afrikaans was developed as language of wider communication in virtually all public domains. Also, considering how the coloured community in the Western Cape was disenfranchised after 1948, attitude changes towards an Afrikaans government and its associated language are, at least on psycho-sociological grounds, understandable. This has certainly contributed to language shift away from the dominant regional language.

\subsection{Language shift as outcome of considered choices}

The decision of parents to enroll their children in E-L1 classes rather than in the A-L1 classes that represent the dominant language of both their community and the region, appears to be an instance of planned and conscious language shift. According to Wei (2000:59), language choice in multilingual communities where there are a number of options "is an 'orderly' social behaviour, rather than a random matter of momentary inclination". Parent and learner interviews in this study confirm this, finding similar responses to Anthonissen and George (2003) which show that many 
A-L1 families in these communities regard English as a language of status and of socio-economic advancement. The perceptions of two learners in the present study regarding the advantages of English, are illustrated in utterances (7) and (8):

(7) English ... the world is more open to you because nowadays most of the jobs is in English and stuff like that.

(8) Because it's like a universal language, everybody knows it right around the world and, like, anyone you can speak to will understand English ...

By introducing their L2 as the LoLT of their children, parents "seem to pre-determine the dominant language for this and future generations" (Farmer 2008:26,27). In utterance (9) one parent expresses the motivation for their choice to raise their child as E-L1, while excerpt (10) presents a learner's perception of the motivation behind her parents' choice of LoLT:

(9) Engelse kinders het beter presteer en dit het gelyk hulle het makliker dinge behaal wat ons nie altyd kon nie. [English children performed better (at school) and it seemd as if they achieved things more easily; things that we couldn't always (achieve).]

(10) Interviewer: So you think at university everything's going to be English?

Learner: $\quad$ Yes. That's why my parents decided to raise me English.

\subsection{Language shift more prevalent in public domains}

Considering the reported use of Afrikaans among parents and grandparents ${ }^{14}$ of School A's learners, one is confronted with a question as to the use of different languages in different domains. Afrikaans is still widely used as family language, as well as in the broader community. Nevertheless, English is the LoLT of increasing numbers of learners from these communities. This raises questions as to where, when and how the learners who participated in this study use the two community languages. Referring to different domains of language use, Fishman (1972: 441) describes domains as "institutional contexts" marked by "congruent behaviour occurrences". Crystal (2003:148), similarly, defines a domain as "a group of institutionalised social situations typically constrained by a common set of behavioural rules". This notion is important when one wants to relate variation in individual choices to broader sociocultural norms and expectations of interaction. Conventions of language choice and language use in different domains such as house, church, office, media and educational institutions, become telling when there are bilingual speakers who migrate between contexts where there are different conventions and related expectations regarding the use of either or both of the two community languages. Where two languages are used side by side in this way, it is inevitable that there will also be a fair amount of code-switching. Learners that took part in the present study also referred to different conventions of language choices and communicative practices among family and peers, as can be seen in (11) and (12):

(11) With my cousins from my mommy's side I talk English. With my daddy's family I talk Afrikaans because they are Afrikaans. Also with my aunties and uncles. Né, Mammie?

(12) Um, if I speak to my friends then, like, maybe Afrikaans 'cause like, mostly I speak Afrikaans to my mommy. English and Afrikaans. But with adults I speak English 'cause I, like, don't wanna make a mistake. 


\subsection{Language shift and code-switching}

Code-mixing and code-switching - practices of intermittently using two linguistic codes in the same conversation - typically occur among bilinguals. Often there is a general assumption that interlocutors are relatively proficient in both languages ${ }^{15}$. Recall examples (2) and (3) in section 4.3 that illustrate code-mixing where words and phrases from the second language are inserted into sentences of the first language. Example (13) below further illustrates code-switching where a learner uses the two languages she knows alternately:

(13) Nee my pa is uit-en-uit Afrikaans. My pa het meestal met ons Afrikaans gepraat. My ma was die een wat die... wat die Engels... Maar kyk, sy was die ... / she was the main figure in the house - when daddy used to talk then it's like ... but we were bilingual, so to me it's just...I can remember that it was mostly English. ${ }^{16}$ [No my dad is Afrikaans through and through. My dad mostly spoke Afrikaans to us. My mother was the one who the ... who the English ... But look, she was the .../ ]

Besides finding systematic ways of matching two different grammatical systems in code-switching, Mesthrie, Swann, Demert and Leap (2000:168) have drawn attention to the way in which bilinguals use both languages together in a way "that is meaningful, drawing on the associations of both languages and indexing dual identities." In the questionnaires as well as during interviews learners not only reported code-switching practices, but also exhibited code-switching which was largely uncontrolled and unconscious in that they did not show awareness or present an apology for "mixing their languages". The practice of code-switching among School A learners does indeed index dual identities: on the one hand it is testimony to the A-L1 of the home environment, and on the other hand it asserts an association with English, the national lingua franca. In interviews learners and parents indicated that English represents greater life chances and higher status.

\subsection{Language shift as a spontaneous process}

According to Fishman (1989:240) abandoning one language in favour of another is only likely if there is a clear advantage for the population undergoing such language shift. If not forcefully imposed, the exercise has to "provide (or promise to provide) entrée to scarce power and resources or there would be little reason for indigenous populations to adopt them for intergroup use, or, by extension, for certain subsequent intragroup use as well." Following this argument, the fact that English is increasingly a preferred LoLT even though it is not obligatory, suggests that there must be associated benefits of power and access to resources for the E-L1 learners from A-L1 families. Such benefits in this region are not only associated with being able to communicate across linguistic boundaries nationally and internationally. The comment by Anthonissen and George (2003) that "(i)n the South African context languages are markers not only of personal, but also of social and political identities" is pertinent here. The interviews with learners and parents disclosed ambiguous attitudes towards Afrikaans. On the one hand, for many Afrikaans remains a "language of the heart" as is clear from utterances such as the following: "dit bly nog steeds my favourite" [it remains my favourite], "...alhoewel jy baie lief was vir jou taal" [even as one was very fond of one's language] (see Anthonissen 2009:65,71). On the other hand, many others associate Afrikaans with a detestable former regime. This has been a strong motivating factor underlying the generational language shift in coloured communities (see Anthonissen and George 2003). The data collected for the present study confirms that such attitudes developed in the first and second generations as spontaneous responses to personal histories of being marginalised, in which association with language is not marginal. These attitudes often implicitly and explicitly underpin the choice of A-L1 parents to 
enrol their children in the E-L1 classes - a choice which the present study found to be overwhelmingly endorsed by the learners themselves.

\section{Conclusion}

In summary, enrollment in the E-L1 classes of a historically Afrikaans school, situated in a bilingual community where Afrikaans is the dominant language, confirmed that for many English is replacing Afrikaans as LoLT. Data provided by teachers of the learners in E-L1 classes further confirmed that a majority of the learners enrolled in the E-L1 group come from Afrikaans homes. Questionnaires filled in by learners, as well as interviews with the learners and a small sample of their parents, confirmed that, although Afrikaans is still widely used as home language, extensive code-switching and code-mixing is common. Such practices contribute to language change among L1 speakers of Afrikaans and of English. The data underscores a preference for English not only as LoLT, but also as a language of wider communication. Nevertheless, in response to specific questions about the possibility of completely replacing Afrikaans as a community language, none of the participants interviewed in this study anticipated a rapid decline of this community language or a scenario in which the area would be identified as home to a monolingual English community. When asked whether they would raise their children as speakers of English only, most learners' answers resembled those in (14) and (15) below:

(14) I think bilingual 'cause that's good, because it gives them both sides of the Cape.

(15) I think bilingual, strongly, but mostly on the English side. I won't like to take Afrikaans away from them.

On the basis of these findings we can conclude that, although Afrikaans seems to be in decline as the home language and first language of the community investigated here, on a local vernacular level it cannot be characterised as a "vanishing voice" (Nettle and Romaine 2000).

\section{Notes}

1. Afrikaans, traditionally seen as dialectally descended from Dutch, has distinctive features more likely introduced by language contact in the $17^{\text {th }}$ and $18^{\text {th }}$ centuries between Dutch colonists and the indigenous Khoe-Khoe, as well as Malay speaking slaves (see Den Besten 1989). Many of the families formerly classified as "coloured" in this region are Muslims of Malaysian/Indonesian descent. This community is considered to be the first to have spoken Afrikaans, therefore it is not surprising that until recently this was the first, and for many also the only language used in the domain of the family.

2. This paper is based on data collected for an MA research project (Farmer 2008).

3. For a more specific discussion of reasons put forward for language choices of Afrikaans families that raise their children in English, see Anthonissen and George (2003) and Anthonissen (2009).

4. This term is contested on a number of grounds such as that it is inaccurate and sometimes offensive; it is used in this study simply to follow its continued use in many public domains. It distinguishes different communities, referring specifically to persons from various racial/ethnic backgrounds, including Muslims, seen to be of mixed race. 
5. Wesbank is a recently established sub-economic housing estate on the Cape flats thus also situated in the Cape Town metropolitan area.

6. A long history of social segregation contributed to the emergence of a variety of Afrikaans used largely by urban, white speakers of the language, as the standard form. Varieties such as "Oranjerivier Afrikaans" and "Kaapse Afrikaans", although not used by coloured speakers only, are popularly associated with coloured communities. Discriminatory practices in all social domains (education, employment, government, etc.) during the $20^{\text {th }}$ century led to stigmatisation of non-standard varieties of Afrikaans, even among L1 speakers of these dialects.

7. In transition to democratic rule, the outgoing government in the late 1980s suggested three models (Models A, B and C), in terms of which formerly white schools would be able to maintain facilities and opportunities that a new, more equal distribution of state support could not guarantee. Models A and B soon proved to be unsustainable and were done away with - leaving all whites-only schools as "Model C" schools for a very brief period before open enrolment, regardless of racial classification, was legislated. After 1994, schools that had formerly catered for white children only and are still held to have better teaching facilities and practices, are referred to as "formerly Model C" even though they no longer use racial classification as entry criteria.

8. This term refers to the classroom of a specially allocated teacher who meets learners for a period in the school day during which administrative issues are dealt with.

9. A number of the learners in the E-L1 classes are from E-L1 and from isiXhosa-L1 homes; a closer look at the linguistic repertoires of the smaller sample of grade 10 and 11 learners as given below, will explain how the E-L1 group is divided in terms of home languages.

10. Of the 389 learners enrolled in grades 10 and 11, 303 were registered in the E-L1 group. All of these learners filled in the questionnaires. Of the 303 in this group, 229 had either Afrikaans or English as home language - other home languages reported include isiXhosa, German, Chinese and Portuguese. Further analyses excluded learners with home languages other than Afrikaans and/or English, since our interest is in perceived language shift in the A-L1/E-L1 communities.

11. In code-switching studies, the dominant language which supplies the main grammatical frame is often called the "matrix language" or "base language", into which elements from the embedded language are inserted. The term "embedded language" refers to the other language(s) which also participate in code-switching, but with a lesser role. (Myers-Scotton 2006).

12. See Anthonissen and George (2003) on "Cape Flats English" which has L2 features, but is regarded by speakers to be completely acceptable in contrast to "Kaapse Afrikaans" where the dialectal features are seen to reflect badly on the speakers.

13. For the uninitiated: 1948 marks the rise to power of the Afrikaans white electorate, and also the advent of the Apartheid policy which entrenched societal divisions and distribution of resources on racial grounds.

14. In the questionnaires 172 of the 229 learners (75\%) with English or Afrikaans as home language, indicated that their parents and grandparents use Afrikaans at home. In the learner interviews, only one of the 20 learners indicated that her grandmother was EL1; all others reported A-L1 grandparents.

15. See Muysken (2000) and Myers-Scotton $(2002,2006)$ for more on various definitions and models of code-switching. 
16. Example (13) has been taken from the data-set collected in 2009 and used in the study by Anthonissen (2009) where Afrikaans parents motivated and justified their decision to bring up their children in English.

\section{References}

Anthonissen, C. 2009. Bilingualism and Language Shift in Western Cape Communities. SPIL PLUS 38: 61-76.

Anthonissen, C. and E. George. 2003. Family Languages: Bilingualism and Language Shift. FIPLV 21st World Congress. Conference proceedings (CD-version). World Federation of Modern Language Associations. Johannesburg: University of Johannesburg.

Crystal, D. 2003. A Dictionary of Linguistics and Phonetics. Fifth edition. Oxford: Blackwell Publishing.

Den Besten, H. 1989. From Khoekhoe foreignertalk via Hottentot Dutch to Afrikaans: the creation of a novel grammar. In Pütz, M. \& René D. (eds). Wheels within wheels. Papers of the Duisburg Symposium on Pidgin and Creole Languages. Frankfurt am Main: Peter Lang. pp. 207-249

Dyers, C. 2008. Truncated Multilingualism or Language Shift? An examination of Language Use in Intimate Domains in a New Non-racial Working Class Township in South Africa. Journal of Multilingual and Multicultural Development 29(2): 110-126.

Farmer, Jean L. 2008. Language choices of English L1 learners in a Western Cape high school. Unpublished MA thesis, Stellenbosch University.

Fishman, J. 1972. Domains and the relationship between micro- and macro-sociolinguistics. In J.J. Gumperz and D. Hymes (eds). Directions in Sociolinguistics. New York: Holt, Rinehart and Winston. pp. 435-53.

Fishman, J. 1989. Language and Ethnicity in Minority Sociolinguistic Perspective. Multilingual Matters: Clevedon

Fishman, J. 2000. Who speaks what language to whom and when. In Li Wei (ed). The Bilingualism Reader. London: Routledge. pp. 95.

McCormick K. 2003. Language in Cape Town's District Six. Oxford, UK: Oxford University Press.

Mesthrie, R., J. Swann, A. Deumert, and W.L. Leap. 2000. Introducing Sociolinguistics. Edinburgh: Edinburgh University Press.

Milroy, L. and P. Muysken. (eds). 1995. One speaker, two languages. Cambridge: Cambridge University Press.

Muysken, P. 2000. Bilingual Speech. A Typology of Code-Mixing.Cambridge: Cambridge University Press.

Myers-Scotton, C. 2000. Code-switching as indexical of social negotiations. In Li Wei (ed). The Bilingualism Reader. London: Routledge.

Myers-Scotton, C. 2006. Multiple Voices. An Introduction to Bilingualism. London: Blackwell Publishing.

Nettle, D. and S. Romaine. 2000. Vanishing Voices - the extinction of the world's languages. Oxford, UK: Oxford University Press.

Romaine, S. 2000. Language in Society (2nd ed). Oxford: Oxford University Press.

Schmied, J. 1991. English in Africa. An Introduction. London: Longman Linguistics Library.

Wardhaugh, R. 2002. An introduction to Sociolinguistics (4th ed.). London: Blackwell Publishers.

Wei, L. 1994. Three Generations Two Languages One Family: Language choice and language shift in a Chinese community in Britain. London: Multilingual Matters. 
Wei, L. (ed). 2000. The Bilingualism Reader. London: Routledge. pp. 14-15, 59-61.

Internet sources:

http://www.statssa.gov.za/publications/statsdownload.asp?PPN=Report-03-02-13\&SCH=3589. Statistics South Africa. Census 2001: Primary tables in Western Cape: Census 1996 and 2001 compared, p.19.

http://www.statssa.gov.za/publications/statsdownload.asp?PPN=StatsInBrief $\& S C H=2360$ Statistics in Brief 2002, pp. 16-18. 
Appendix 1. Questionnaire for learners

\section{SECTION 1 - RESPONDENT BACKGROUND}

Name and Surname:

Gender: Female

Age:

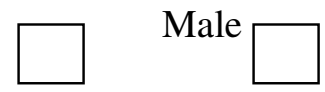

Primary School attended:

Language of instruction at Primary School:

1. Which of the languages given below do you know? Use a number on a scale of 1 to 5 to indicate how you rate your ability in each column:

$1=$ very good, $2=$ good, $3=$ satisfactory, $4=$ not good, $5=$ not at all

\begin{tabular}{|l|l|l|l|l|}
\hline & Speak & Listen \& Comprehend & Read & Write \\
\hline English & & & & \\
\hline Afrikaans & & & & \\
\hline Xhosa & & & & \\
\hline $\begin{array}{l}\text { Other (specify } \\
\text { which) }\end{array}$ & & & & \\
\hline
\end{tabular}

2. Which language do you use in each context? (Use a $\sqrt{ }$ in appropriate column)

\begin{tabular}{|l|l|l|l|l|l|}
\hline & Classroom & $\begin{array}{l}\text { School } \\
\text { grounds }\end{array}$ & Parents & $\begin{array}{l}\text { Peers (outside } \\
\text { school) }\end{array}$ & $\begin{array}{l}\text { Religious } \\
\text { context }\end{array}$ \\
\hline English & & & & & \\
\hline Afrikaans & & & & & \\
\hline Xhosa & & & & & \\
\hline $\begin{array}{l}\text { Other language } \\
\text { (specify which) }\end{array}$ & & & & & \\
\hline $\begin{array}{l}\text { I use more than one } \\
\text { language } \\
\text { (specify which } \\
\text { ones) }\end{array}$ & & & & & \\
\hline
\end{tabular}


3.1 English is your language of instruction. Is English also your language of learning?

\begin{tabular}{|l|l|}
\hline Yes & \\
\hline No & \\
\hline Sometimes & \\
\hline
\end{tabular}

3.2 If you answered no or sometimes, which other language do you use in learning?

\begin{tabular}{|l|l|}
\hline Afrikaans & \\
\hline Xhosa & \\
\hline $\begin{array}{l}\text { Other } \\
\text { (specify) }\end{array}$ & \\
\hline
\end{tabular}

4. Which languages do your family use at home?

\begin{tabular}{|l|l|l|l|l|}
\hline & Siblings & Parents & Grandparents & Other members \\
\hline English & & & & \\
\hline Afrikaans & & & & \\
\hline Xhosa & & & & \\
\hline Other (specify) & & & & \\
\hline & & & & \\
\hline
\end{tabular}

5.1 As a bilingual speaker of English and Afrikaans or English and Xhosa, which of the two is your strongest?

\begin{tabular}{|l|l|}
\hline English & \\
\hline Afrikaans & \\
\hline
\end{tabular}

$$
\text { OR }
$$

\begin{tabular}{|l|l|}
\hline English & \\
\hline Xhosa & \\
\hline
\end{tabular}


5.2 Do you use the same language with your family at home as you do at school with friends?

\begin{tabular}{|l|l|}
\hline No & \\
\hline Yes & \\
\hline
\end{tabular}

If you answered NO, please explain:

6.1 If you had a choice now, would you prefer your schooling through medium of:

\begin{tabular}{|l|l|}
\hline English & \\
\hline Afrikaans & \\
\hline Xhosa & \\
\hline
\end{tabular}

Give reasons for your preference. 
Appendix 2. Learner and parent interview schedules

\section{Learner Interview Schedule}

1. Which languages do you speak, read and write?

2. Which of these languages are you better at in (a) speaking (b) reading (c) writing?

3. Am I right that you often use Afrikaans with friends, your brothers and sisters, your parents and at church/mosque? Is Afrikaans or English the language you feel most comfortable speaking? Can you give me a reason for your answer?

4. English is your main language at school. Do you sometimes find it difficult to use English at school and Afrikaans at other times/places?

5. Do you have friends who speak Afrikaans only?

6. What language is used at the church/mosque you attend?

7. What interests/activities do you have after school hours? What language is used during these activities?

8. What do you plan to do after school? Do you think you will be using Afrikaans and English in your further studies or working life?

9. If you could choose again, which of your two languages would you have preferred as your main language in all spheres (academically and socially)? Can you give me a reason for your answer?

10. I do not know how you are performing academically. Do you think that you would have done better at school if you had been placed in an Afrikaans First Language class, seeing that your parents speak Afrikaans at home?

11. Which language would you prefer to use in raising your children one day? Why?

\section{Parent Interview Schedule}

1. Which language/s do you speak to your children?

2. Which language/s do your children speak to you?

3. Which language/s do your children use when they are on their own, as in grumbling, crying out, calculating or counting to themselves - thus in their "private domain"? 
4. Which language/s do your children use with their friends?

5. Which language/s do other older family and community members use with your children?

6. Why did you decide to enroll your children in the E-L1 group at an ex-model C school?

7. Which language/s did your parents speak to you while you were growing up?

8. Are you aware of your children's attitudes towards their different languages? Would you like to comment on their language attitudes? 